\title{
Challenges for Child Mental Health Raised by School Closure and Home Confinement During the COVID-19 Pandemic
}

\author{
Betty Pfefferbaum ${ }^{1}$
}

Accepted: 12 July 2021 / Published online: 16 August 2021

(c) The Author(s), under exclusive licence to Springer Science+Business Media, LLC, part of Springer Nature 2021

\begin{abstract}
Purpose of Review The closure of schools during the COVID-19 pandemic has interrupted the education of children worldwide. This paper reviews the psychological effects of this action on children and the impact on school-based services.

Recent Findings Emerging epidemiologic findings have generated an intense debate about the need for, and potential benefit of, school closure in the context of COVID-19. International research reveals reactions in children that are not typically considered in the disaster literature as well as those that arise in other disasters. School closure also has curtailed the delivery of mental health services commonly offered in schools.

Summary The debate about school closure will likely persist depending on local disease conditions and school readiness. Moreover, school closure is a possibility in future epidemics and pandemics and other disasters. The benefit of school closure must be balanced against the risk to children's education and psychosocial development.
\end{abstract}

Keywords Children $\cdot$ COVID-19 $\cdot$ Disaster $\cdot$ Pandemic $\cdot$ Public health $\cdot$ School closure

\section{Introduction}

As part of global public health measures to address the spread of COVID-19, the closure of schools has interrupted the education of over one billion students worldwide [1] and underscored the importance of school in children's lives. In addition to advancing their intellectual and academic growth, school is a fundamental component in support of children's physical, emotional, family, social, and moral development. As part of the foundation of communities, school also contributes to child, family, and communal functioning. Not only are schools responsible for educating a community's children, they provide a venue for delivering health, mental health, and social services to children, and they create a nexus of social life for families and communi-

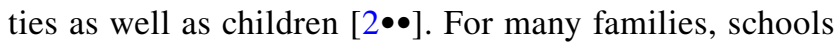

This articleis part of the Topical Collection on Child and Family Disaster Psychiatry

Betty Pfefferbaum

Betty-Pfefferbaum@ouhsc.edu

1 Department of Psychiatry and Behavioral Sciences, College of Medicine, George Lynn Cross Research Professor Emeritus, University of Oklahoma Health Sciences Center, Oklahoma, USA function as de facto child care providers before, during, and after the school day, and schools constitute an important

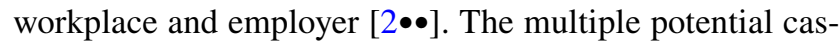
cading effects of widespread school closure on children's social, emotional, behavioral, and physical health; on their families; and on communities and society have generated an intense debate about the appropriateness of the action, especially in light of available evidence about the transmission of the virus in children.

\section{Effects of School Closure}

The widespread closure of schools during the COVID-19 pandemic has required remote learning which has resulted in decreased social interactions and extra-curricular and athletic activities; in added social and economic burden and stress for families; and in the interruption of numerous school-based social, health, and mental health services. Many parents have either stayed home or identified alternative childcare arrangements, often leading to reduced employment or unemployment. These hardships are particularly pronounced for already disadvantaged families most endangered by economic loss [3], many of whom also lack the needed equipment and technologies to support their children's learning at home [4]. Similarly, schools in 
disadvantaged areas are especially compromised by a lack of fiscal assets and reserves needed to improve facilities and staffing in response to the pandemic [5]. All of these consequences have increased extant health, economic, and social disparities exposed by the pandemic [3].

\section{The Current Paper}

With emerging research and knowledge about the epidemiology of COVID-19 in children and about the relative risks and benefits of school closure, many schools have reopened or partially reopened or are planning to reopen. In the face of new evidence about the susceptibility of children to the virus, about new variants (some more infective and virulent), about vaccination hesitancy, and about noncompliance with physical distancing and other public health containment measures, concerns related to school closure persist. This paper reviews the epidemiology of the disease in children and implications for school closure, academic consequences and the challenges associated with remote learning, the emotional and behavioral outcomes associated with the pandemic and school closure, and the role of schools in mental health and disaster mental health services for children. Finally, considerations are offered for the reopening of schools.

\section{Epidemiologic Considerations of COVID-19 in Children and Implications for School Closure}

Decisions regarding school closure have been based largely on experiences with other common respiratory viruses like influenza [6•] for which school closure may be effective in controlling the spread of disease, especially when disease

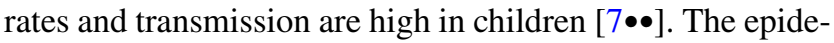
miology of COVID-19 is not fully known, and reports of children's susceptibility and of the transmission of the virus in children are inconsistent. Some have concluded that children are less likely to contract and spread the disease $[3,8 \bullet]$ while others have noted that despite milder symptoms and lower mortality in children, they are as likely as adults to contract the disease, and they may be carriers [9]. A recent review and meta-analysis offered preliminary evidence that young children (aged 10 to 14 years and younger) are less susceptible to the COVID-19 virus and weak evidence that they are less likely than adults to transmit the virus but noted that more research is needed to fully understand the epidemiology and transmission dynamics of COVID-19 in children [8•]. The emergence of new variants and a growing knowledge base suggest that the evidence may continue to change over time.

\section{Effectiveness of School Closure}

The benefit of school closure relative to other containment measures is unclear. A population-based study in the United States (U.S.) during a 60-day period beginning in March 2020, relative to baseline data beginning in January 2020, revealed a negative association of school closure with COVID-19 incidence and with COVID19-related mortality, but the associations were stronger with voluntary behavioral changes (e.g., reduced time at the workplace and restaurant dining) than with school closure [10]. Using similar data and methodology, Auger and colleagues [11] also found that the incidence of COVID-19 and related mortality decreased with school closure, while Courtemanche and colleagues [12] found no association of school closure with the incidence of COVID-19 or with related mortality, but these studies failed to control for other voluntary behavior changes. A recent study of COVID-19 across three waves of the pandemic in Hong Kong revealed that transmission within schools was rare and concluded that the primary source of infection was through household members rather than schools [13]. A review of the literature on school closure and physical distancing measures found no data on the benefit of school closure on transmission relative to other measures and noted that modeling studies suggest that other physical distancing measures would be as effective $[7 \bullet \bullet]$. These findings raise questions about both the need for, and potential benefit of, school closure and suggest that other approaches within schools (e.g., discontinuing non-essential activities, reducing class size, increasing the distance between students, and restricting children to contained cohorts; emphasizing hygiene; effective ventilation) [7••] and in communities (e.g., requiring mask wearing, travel restrictions) [13] may obviate the need for school

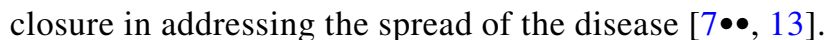

Using case-based epidemiological data and the scientific literature, a technical report published by the European Centre for Disease Prevention and Control (ECDC) [14•] in August 2020 concluded that child-to-child transmission of the virus in schools is infrequent, especially in preschool and primary school, and not the major cause of infection in those who become infected while they are in school. The ECDC [14•] noted that observational evidence indicates that reopening schools has not resulted in significant community spread but acknowledged that it may be difficult to detect infectious outbreaks in schools given the relative absence of symptoms in children.

Reviewing information from countries that have been effective in reopening schools, Melnick and colleagues [15] reported that, in general, the decision to reopen schools was made when community infection had declined 
and other sectors had begun to reopen. Thus, they cautioned that success in the reopening of schools may differ across communities based on local infection rates and on the extent to which other measures, such as testing and contact tracing, are in place [15]. Awaiting more definitive data, the ECDC [14•] recommended that decisions about school closure and reopening reflect decisions about other public health measures implemented more broadly within the community. Faust and Munro [16] noted that while research continues to explore the transmission dynamics of the virus in schools, no conclusive results will be available immediately. In its 2021 guidance for school reentry, the American Academy of Pediatrics [6•] also endorsed the need for additional research, especially in light of the fact that transmission in older children may be similar to that of adults and in the absence of information on the potential complexities for children with disabilities and pre-existing medical conditions. Ultimately, decisions about reopening should be based on information about transmission in the local community, the ability of schools to implement preventive measures, and the needs and views of children and families [16].

\section{U.S. Parents' Plans to Send Their Children Back to School}

Amid differences among schools in their decisions regarding offering in-person, remote, or hybrid classes as well as differences in mitigation measures, studies have examined parents' plans regarding sending their children back to school. Research conducted in June 2020 revealed that while many U.S. parents planned to send their children back to school in the fall of 2020 [17•] or for the 2020-2021 school year [18], a sizeable minority did not plan to do so $[17 \bullet, 18]$. Factors associated with plans to keep their children at home included lower income, younger children, vulnerable household members and vulnerable children, and fear of COVID-19 [17•]. Confidence in the school system and challenges of homeschooling were negatively associated with plans to keep their children at home [17•]. Participant-reported unemployment and flexible employment were associated with plans to keep children at home [17•] while full and part-time employment were associated with plans to send children back to school [18].

A study of a nationally representative sample of U.S. parents of school-aged children, conducted in July 2020, examined differences in parental attitudes about school reopening across racial/ethnic groups [19]. Most parents were concerned about the effect of the COVID-19 pandemic on the quality of their children's education, and over one-half agreed that school should reopen in the fall of 2020, but there were differences across racial/ethnic groups with more White than minority parents favoring school reopening [19].
Racial/ethnic disparities in socioeconomics, access to services, and health outcomes along with discrimination have influenced COVID-19 morbidity and mortality, and socioeconomically and other disadvantaged families have fewer resources to support homeschooling [19]. No known empirical studies have examined the influence of the recent surge in racial tensions and racially based community violence on parent, student, and educator attitudes and concerns about school reopening, but this should be addressed as schools consider options for educational and other services for children in the context of COVID-19.

Parents in one study endorsed a range of school mitigation measures including daily temperature screening when students arrived at school and required testing for students if a classmate in the same classroom tested positive for COVID-19 [18]. These findings have important implications for both families and schools which must contemplate how to provide for the needs of students being homeschooled, especially given that parents may assume that resources will be made available for homeschooling [17•]. Thus, schools must communicate with families about what will be provided and about the requirements for homeschooling [17•]. These findings for the 2020-2021 school year [17•,18] are instructive and may provide useful information to address remote learning if needed in future pandemics and other disasters as well as in the current pandemic if changes occur that require schools to revisit their decisions.

\section{Academic Consequences and Challenges of Remote Learning}

Long-lasting school closure has potentially serious effects on children's academic progress [20,21]. For example, a study using a large national U.S. database on students in grades 3 to 8 projected losses in learning gains for reading and mathematics for students returning to school in the fall of 2020 [22•]. There was some variability in outcomes, however, with some students making gains in reading, perhaps due to differences in support from parents and educators [22•]. Students with the greatest losses may experience the greatest recovery during the 2020-2021 school year though the potential for academic growth may be associated with health, economic, and psychological consequences of the pandemic [22•]. Another study of primary school performance on national examinations in a large sample from The Netherlands, which compared student achievement before and after the nation's 8-week COVID-19-related school closure with similar data from the prior 3 years, revealed a loss of approximately three percentile points or one-fifth of a school year-the same time period that schools were closed [23]. Schools in The Netherlands are equitably funded and well prepared for technologic educational processes, but students, parents, and educational 
staff had little time to prepare and adjust [23]. There was considerable variation in learning loss across schools, with students from less-educated families experiencing up to $60 \%$ greater losses than those from better-educated families [23]. Arguing that the results reflect the accumulated effect of acquired knowledge, the authors suggest that students did not benefit from home-based learning [23]. It is unclear how enduring these changes will be [23].

Schools have been inconsistent in their approaches to minimizing the adverse effects of closure [20]. Some schools rapidly implemented virtual programming and processes including providing equipment and online education and curricula. Others, especially in rural and low-income areas, were unable to meet the challenge of remote education [20]. The use of electronic technology in education had gained popularity before the pandemic [24], but extensive home confinement hastened its use [25]. Advantages of online learning include access to large amounts and a diversity of information as well as flexibility in scheduling and in the pace of study $[25,26]$. The costs to families may be prohibitive, however, for those lacking the necessary equipment and other resources (e.g., internet access, instructional support) $[24,25]$ to use the technology effectively [25] and for parents who are unable to supervise and monitor their children's progress during home confinement [20]. The challenges of remote learning are particularly problematic for disadvantaged and minority families [6•] and are likely to increase social and economic disparities as vulnerable children fall further behind in their education. In addition, at the onset of the pandemic, many parents, children, and teachers were ill prepared to use online technology [24, 26], and many neither appreciated nor endorsed its use [26]. Remote learning also has required teachers to manage new and additional demands on their time, create engaging curricula and coursework in different formats, learn and apply alternative teaching methods, and find novel ways to address the needs of individual students [25]. Unfortunately, standards for the quality of online coursework and resources have not yet been developed and promulgated [25]. As online technology assumes its place in the modern and future educational ecology [26], the experiences and lessons learned during this pandemic provide opportunities to create alternative educational processes and products and to encourage their use in the future including in the context of other disasters.

\section{Emotional and Behavioral Outcomes of School Closure}

Research has explored the emotional and behavioral outcomes associated with COVID-19 in children. In many respects, these outcomes mirror those of other disasters, but the pandemic, and the associated containment measures (including school closure), have generated a number of new concerns.

\section{Psychological Consequences}

Publications from countries around the world have called attention to the social, emotional, and behavioral effects of the COVID-19 pandemic and of school closure and home confinement. Parents have reported a number of reactions in their children that are not atypical of children's reactions to other disasters. These include fear [27], anxiety [28], worry [28, 29], nervousness [28, 29], clinging behavior [27], restlessness [28, 29], irritability [27-29], and attention [27] and concentration [29] difficulties. Other reactions such as boredom [28, 29] and loneliness [29] are more specific to school closure and home confinement and have not been addressed in the literature on prior disasters.

Some children are particularly vulnerable to school closure and home confinement including children who are socially and economically disadvantaged (including the homeless and undocumented immigrants); those with physical illnesses, physical disabilities, and/or cognitive disabilities; those with mental disorders or whose parents suffer mental disorders; those whose family members have contracted COVID-19; and those whose parents are essential workers. Many of these children are generally vulnerable, and many would have received school-based educational, social, health, and mental health services prior to school closure. For example, a longitudinal study of primary school students (4 to 8 years of age) with emergent mental health problems found that increased problems in children during the pandemic relative to pre-pandemic levels were related to parental mental health which was affected by family financial stress [30].

Some children may actually do better psychologically, at least temporarily, during home confinement. A study of predominantly Hispanic public charter school students in grades 5 to 8 found low rates of new-onset emotional distress in the first several months after their school closed [31]. Prepandemic mental health problems decreased during school closure in those with elevated pre-pandemic problems while those without elevated pre-pandemic problems experienced a decrease in internalizing and total problems and no change in externalizing or attention problems [31]. Lower symptom levels during this period were associated with better family functioning perhaps due to increased time with family and opportunities to build family relationships, decreased stress associated with peer interactions, reduced academic pressure, improved sleep associated with more flexible schedules, and the school and social support in this community [31]. It was unclear how long these positive outcomes would be sustained. 


\section{Changes in Lifestyle Behaviors}

The closure of schools during the pandemic has raised concern about potentially negative implications for children's lifestyle behaviors (e.g., physical activity, diet, media consumption) on their health and mental health. In general, children are less active physically when they are not in school [32], and they tend to gain weight during summer recess when school is not in session [33•-35]. Research has linked sedentary behavior to adverse health outcomesincluding diet and weight concern [35, 36] - and to adverse psychological outcomes while physical activity appears to be associated with beneficial mental health effects [36, 37] including improved self-esteem, cognitive functioning, and academic achievement and decreased depression and anxiety [36].

Much of children's physical activity occurs in connection with school including, for example, during transit from home to school and back, physical education classes and athletics, and recess [32]. COVID-19 public health measures including school closure, home confinement, and physical distancing have decreased opportunities for physical activity, especially for those living in cramped dwellings [33•, 35]. Children are less likely to frequent venues that support physical activity, such as parks and playgrounds, thus increasing sedentary behavior [35], screen time [32, 35], and weight gain and obesity [35]. These COVID-19 public health measures, along with interruptions in school-based nutritional programs (e.g., subsidized meals), also have reinforced stockpiling and the consumption of unhealthy processed and highly caloric food [33, 35] and likely have increased food insecurity for many which also is associated with childhood obesity [35].

COVID-19 studies from various countries have found decreased physical activity and increased screen time with home confinement in children and adolescents [28, 29, 38]. These consequences may be particularly important for obese children $[35,39,40]$. Impoverished children are at greater risk because their living situations make physical distancing more difficult; they have fewer opportunities for physical activity, and they often have fewer healthy food options $[33,35]$.

\section{School Services}

While education is their primary mission, schools constitute a key venue for delivering a multitude of services especially important for disadvantaged and vulnerable children $[4,5$, 41]. These services address children's nutritional, health, public health, and mental health needs and provide entree to a safety net for social services (e.g., child welfare) for those threatened by neglect, abuse, and domestic violence $[4,5,41]$. Thus, for many children and families, especially disadvantaged children, school closure and diminished access to school services have far-reaching consequences that extend beyond disrupted education.

Schools are an ideal setting for accessing large numbers of children in a familiar, comfortable, and trusted setting where children spend much of their waking day. Situating services in schools may decrease the stigma associated with them and increase their acceptability and accessibility. Transportation and scheduling problems can be minimized, and parents are less burdened by the responsibility for identifying providers.

\section{Mental Health Services}

Children's psychological problems are likely to surface in school and can affect academic functioning, and poor academic functioning can affect children's mental health [42]. Unfortunately, many children who experience mental health problems receive no services for those problems [42]. Worldwide, both in low and middle [43] and in high [44] income countries, schools constitute a venue for a range of mental health promotion, prevention, and treatment interventions. A study of mental health services in educational and non-educational settings in the U.S. found that almost $60 \%$ of adolescents who utilized mental health services received services in educational settings and that more than one-third utilized these services exclusively in educational settings . Use of school-based services was particularly important for those from low-income and racial/ethnic minority families dependent on publicly funded health insurance (e.g., Medicaid/CHIP) [45].

Reviews and meta-analyses of a variety of school-based interventions support their use for a range of child mental health problems [42, 46, 47]. School services include preventive interventions for both students in general and those with mental health conditions. These interventions can be categorized according to the child's risk for mental health problems [48]. Universal interventions are intended for all children in the population (e.g., entire classroom, entire schoo [43] regardless of their risk [42, 43, 48]. Selective interventions, which may require screening to identify appropriate students $[42,48]$, are for children with elevated biological, psychological, and/or social risk (e.g., based on socioeconomic status, temperament, exposure to trauma) for developing a mental disorder [42] but no clinical manifestations [42]. Indicated interventions are for children with clinical symptoms who do not meet full diagnostic criteria for a disorder $[42,48]$.

\section{Disaster Mental Health Services}

As with mental health services in general, disaster mental health services are commonly delivered in schools. In fact, a qualitative review of interventions delivered 
to children in the context of natural and made-made disasters revealed that over $70 \%$ of the 48 interventions evaluated were delivered in schools [49]. School-based child disaster mental health interventions span all disaster phases from pre-event preparedness activities to early interventions and throughout recovery for months to years post event. Interventions appropriate for administration in schools include psychological first aid, psychoeducation, and social support as well as screening and assessment to identify and monitor affected children and to triage and refer those needing more comprehensive evaluation and clinical treatment. In general, psychoeducational and supportive interventions can be administered by teachers and paraprofessionals while clinicians are needed to deliver interventions for highly symptomatic children. While not all child disaster interventions are appropriate for delivery in schools by non-clinicians, a meta-analysis of posttraumatic stress outcomes found that school-based interventions administered by teachers and paraprofessionals were beneficial for children exposed to disasters [50].

A number of barriers complicate the delivery of disaster mental health services in schools. The primary mission of schools is education, requiring school administrators and personnel to maintain a focus on academics while also addressing the emotional disaster-related needs of children, teachers, and staff. School personnel may be unaware of the sometimessubtle disaster reactions of children and therefore minimize the effects of a disaster while others may fear that addressing the disaster will increase distress. Many schools have limited access to the resources needed to deliver services including mental health professionals, training for teachers, and space to administer confidential assessment and intervention. Moreover, teachers and staff are likely to be stressed by the disaster; addressing their needs should be among a school's priorities.

\section{Considerations for School Reopening}

Recognizing the advantages of in-person education, especially for young children, the American Academy of Pediatrics [6•] issued guidance for school reopening. The guidance, which acknowledged that any measures may reduce - but not necessarily eliminate - the risk of transmission, was based on a set of principles that included controlling the spread of the virus, instituting flexible developmentally appropriate protective policies and strategies that can be modified depending on changing circumstances, coordinating with health authorities and medical professionals, considering language and diversity in communications, and addressing the needs of the most vulnerable students and of staff $[6 \bullet]$. The guidance also recommended that school personnel be trained to provide emotional support to students, that the emotional needs of staff be addressed, and that mental health staff assist with messaging and communication [6•]. Calling for public health authorities to base decisions about school reopening on scientific evidence and community circumstances, the American Academy of Child and Adolescent Psychiatry and the American Psychiatric Association [51] underscored the need for attention to social as well as educational objectives and to the mental health needs of students, families, and staff. Supplemental resources may be necessary to modify educational practices for children with special needs (e.g., physical, learning, and/ or emotional disability; socioeconomic vulnerability) and for fair and equitable access to technologic equipment and services for disadvantaged children [51].

\section{Conclusions}

The debate about the benefit of widespread school closure in response to the COVID-19 pandemic has not been settled and will likely persist as emerging information about the susceptibility of children to the virus and new variants, coupled with vaccine hesitancy and non-compliance with public health measures, complicates decisions about policy and practice. At the center of the discussion is the need to balance approaches to disease containment with the educational, social, and mental health needs of children and the repercussions on their families and communities. Unfortunately, decisions about school closure and reopening must be made in the context of uncertainty and risk. Lack of familiarity with the disease makes living with the uncertainties and risks all the more difficult.

Even after schools generally reopen, the potential need for intermittent or partial closure is great depending on local disease conditions (e.g., incidence, prevalence) and school readiness. Moreover, school closure in the context of future disease epidemics and pandemics is a realistic possibility, especially in light of distinct disease epidemiology and transmission. School closure also may be necessary when property damage due to more traditional natural and man-made disasters require accommodations for remote learning at home and in other settings. Thus, solutions to the challenges raised in the context of COVID-19 may be instructive for future situations.

Acknowledgements The editors would like to thank Dr. Marleen Wong for taking the time to review this article.

\section{Compliance with Ethical Standards}

Conflict of Interest The author declares no competing interests. Human and Animal Rights and Informed Consent.

This article does not contain any studies with human or animal subjects performed by any of the authors. 


\section{References}

Papers of particular interest, published recently, have been highlighted as:

- Of importance

$\bullet$ Of major importance

1. Inter-Agency Standing Committee (IASC), Reference Group on Mental Health and Psychosocial Support. Operational considerations for multisectoral mental health and psychosocial support programmes during the COVID-19 pandemic. 2020, June. https://interagencystandingcommittee.org/iasc-reference-groupmental-health-and-psychosocial-support-emergency-settings/ iasc-guidance-operational-considerations-multisectoral-mentalhealth-and-psychosocial-support. Accessed 10 May 2021.

2.• National Academies of Sciences, Engineering, and Medicine. Reopening K-12 schools during the COVID-19 pandemic: Prioritizing health, equity, and communities. 2020. The National Academies Press. https://doi.org/10.17226/25858. This consensus report offers evidence-based guidance for reopening schools that considers the physical and emotional health and well-being of students, staff, and communities and the role of schools to aid decision-makers in the context of the COVID-19 pandemic.

3. Esposito S, Principi N. School closure during the coronavirus disease 2019 (COVID-19) pandemic. An effective intervention at the global level? JAMA Pediatr. 2020;174(10):9212. https://doi.org/10.1001/jamapediatrics.2020.1892.

4. Sharfstein JM, Morphew CC. The urgency and challenge of opening K-12 schools in the Fall of 2020. 2020;324(2):1334. https://doi.org/10.1001/jama.2020.10175.

5. Dibner KA, Schweingruber HA, Christakis DA. Reopening K-12 schools during the COVID-19 pandemic. A report from the National Academies of Sciences, Engineering, and Medicine. JAMA. 2020;324(9):833-4. https://doi.org/10.1001/ jama.2020.14745.

6. American Academy of Pediatrics (AAP). COVID-19 Guidance for Safe Schools. 2021. https://services.aap.org/en/ pages/2019-novel-coronavirus-covid-19-infections/clinicalguidance/covid-19-planning-considerations-return-to-inperson-education-in-schools/. Accessed 12 May 2021. This document uses available evidence to offer guidance in support of communities, local education and public health leaders, and pediatricians in devising policies to promote the health of students, educators, staff, and communities during the COVID-19 pandemic.

7.•• Viner RM, Russell SJ, Croker H, Packer J, Ward J, Stansfield C, et al. School closure and management practices during coronavirus outbreaks including COVID-19: a rapid systematic review. Lancet Child Adolesc Health. 2020;4(5):397-404. https://doi. org/10.1016/s2352-4642(20)30095-x. This paper reviews the literature and modeling studies on the effectiveness of school closures and other practices to address the COVID-19 pandemic and recommends that other less restrictive measures be considered in this context.

8. Viner RM, Mytton OT, Bonell C, Melendez-Torres GJ, Ward J, Hudson L, et al. Susceptibility to SARS-CoV-2 infection among children and adolescents compared with adults. A systematic review and meta-analysis. JAMA Pediatr. 2021;175(2):14356. https://doi.org/10.1001/jamapediatrics.2020.4573. This review and meta-analysis found preliminary evidence that children are less susceptible to COVID-19 than are adults and weak evidence that children are less likely to transmit the disease than adults.
9. Aleebrahim-Dehkordi E, Soveyzi F, Deravi N, Rabbani Z, Saghazadeh A, Rezaei N. Human coronaviruses SARS-CoV, MERS-CoV, and SARS-CoV-2 in children. J Pediatr Nurs. 2021;56:70-9. https://doi. org/10.1016/j.pedn.2020.10.020.

10. Zimmerman FJ, Anderson NW. Association of the timing of school closings and behavioral changes with the evolution of the coronavirus disease 2019 pandemic in the US. JAMA Pediatr. 2021;175(5):501-9. https://doi.org/10.1001/jamapediatrics.2020. 6371.

11. Auger KA, Shah SS, Richardson T, Hartley D, Hall M, Warniment A, et al. Association between statewide school closure and COVID19 incidence and mortality in the US. JAMA. 2020;324(9):859-70. https://doi.org/10.1001/jama.2020.14348.

12. Courtemanche C, Garuccio J, Le A, Pinkston J, Yelowitz A. Strong social distancing measures in the United States reduced the COVID-19 growth rate. Health Aff. 2020;39(7):1237-46. https://doi.org/10.1377/hlthaff.2020.00608.

13. Chua GT, Wong JSC, Lam I, Ho PPK, Chan WH, Yau FYS, et al. Clinical characteristics and transmission of COVID-19 in children and youths during 3 waves of outbreaks in Hong Kong. JAMA Netw Open. 2021;4(5): e218824. https://doi.org/10.1001/ jamanetworkopen.2021.8824.

14. European Center for Disease Prevention and Control. COVID-19 in children and the role of school settings in COVID-19 transmission. 2020. https://www.ecdc.europa.eu/sites/default/files/ documents/COVID-19-schools-transmission-August $\% 202020$. pdf. Accessed 8 May 2021. This technical report presents a summary the epidemiology and disease characteristics of COVID-19 in European children and the role of schools in transmission of the disease and describes the effect of school closures on children's health and well-being.

15. Melnick H, Darling-Hammond L. Reopening schools in the context of COVID-19: health and safety guidelines from other countries. Policy brief. 2020. Learning Policy Institute. https:// learningpolicyinstitute.org/product/reopening-schools-covid19-brief. Accessed 10 May 2021.

16. Faust SN, Munro APS. It's time to put children and young people first during the global COVID-19 pandemic. JAMA Pediatr. 2021;175(2):127-8. https://doi.org/10.1001/jamapediatrics.2020. 4582.

17. Kroshus E, Hawrilenko M, Tandon PS, Christakis DA. Plans of US parents regarding school attendance for their children in the Fall of 2020. A national survey JAMA Pediatr. 2020;174(11):1093-101. https://doi.org/10.1001/jamapediactrics. 2020.3864. This study conducted in June 2020 revealed that while many parents planned to send their children back to school in the fall of $\mathbf{2 0 2 0}$, a sizeable minority did not and that these plans were associated with family income and parent employment status, child age and vulnerability, parent fear and confidence in the school system, and challenges of homeschooling.

18. Chua KP, DeJonckheere M, Reeves SL, Tribble AC, Prosser LA. Factors associated with school attendance plans and support for COVID-19 risk mitigation measures among parents and guardians. Acad Pediatr. 2021;21(4):684-93. https://doi.org/10.1016/j. acap.2020.11.017.

19. Gilbert LK, Strine TW, Szucs LE, Crawford TN, Parks SE, Barradas DT, et al. Racial and ethnic differences in parental attitudes and concerns about school reopening during the COVID-19 pandemic — United States, July 2020. Morbidity and Mortality Weekly Report. 2020;69:1848-52. https://doi.org/ 10.15585/mmwr.mm6949a2externalicon.

20. Cardenas MC, Bustos SS, Chakraborty R. A 'parallel pandemic': the psychosocial burden of COVID-19 in children and adolescents. Acta Paediatr. 2020;109(11):2187-8. https://doi.org/10.1111/apa. 15536. 
21. Poletti M, Raballo A. Coronavirus disease 2019 and effects of school closure for children and their families. JAMA Pediatr. 2021;175(2):210. https://doi.org/10.1001/jamapediatrics.2020. 3586.

22.• Kuhfeld M, Soland J, Tarasawa B, Johnson A, Ruzek E, Liu J. Projecting the potential impact of COVID-19 school closures on academic achievement. Educ Res. 2020;49(8):549-65. https:// doi.org/10.3102/0013189x20965918. This study used the literature on absenteeism and on summer learning patterns of five million students in the U.S. to project COVID-19-related learning losses in returning students in the fall of 2020 relative to a typical school year.

23. Engzell P, Frey A, Verhagen MD. Learning loss due to school closures during the COVID-19 pandemic. PNAS. 2021;118(17): e2022376118. https://doi.org/10.1073/pnas.2022376118.

24. Black E, Ferdig R, Thompson LA. K-12 virtual schooling, COVID-19, and student success. JAMA Pediatr. 2021;175(2):119 20. https://doi.org/10.1001/jamapediatrics.2020.3800.

25. Dhawan S. Online learning: a panacea in the time of COVID-19 crisis. J Educ Technol. 2020;49(1):5-22. https://doi.org/10.1177/ 0047239520934018

26. Dong C, Cao S, Li H. Young children's online learning during COVID-19 pandemic: Chinese parents' beliefs and attitudes. Child Youth Serv Rev. 2020;118: 105440. https://doi.org/10. 1016/j.childyouth.2020.105440.

27. Jiao WY, Wang LN, Liu J, Fang SF, Jiao FY, Pettoello-Mantovani $\mathrm{M}$, Somekh E. Behavioral and emotional disorders in children during the COVID-19 pandemic. J Pediatr. 2020;221:264-6. https:// doi.org/10.1016/j.jpeds.2020.03.013.

28. Francisco R, Pedro M, Delvecchio E, Espada JP, Morales A, Mazzeschi C, Orgilés M. Psychological symptoms and behavioral changes in children and adolescents during the early phase of COVID-19 quarantine in three European countries. Front Psychiatry. 2020;11:1-14. https://doi.org/10.3389/fpsyt.2020. 570164.

29. Orgilés M, Morales A, Delvecchio E, Mazzeschi C, Espada JP. Immediate psychological effects of the COVID-19 quarantine in youth from Italy and Spain. Front Psychol. 2020;11:1-10. https://doi.org/10.31234/osf.io/qaz9w.

30. Adegboye D, Williams F, Collishaw S, Shelton K, Langley K, Hobson C, et al. Understanding why the COVID-19 pandemicrelated lockdown increases mental health difficulties in vulnerable young children. JCPP Adv. 2021;1-8. Doi: https://doi.org/ $10.1111 /$ jcv2.12005.

31. Penner F, Ortiz JH, Sharp C. Change in youth mental health during the COVID-19 pandemic in a majority Hispanic/Latinx US sample. J Am Acad Child Adoles Psychiatry. 2021;60(4):51323. https://doi.org/10.1016/j.jaac.2020.12.027.

32. Guan H, Okely AD, Aguilar-Farias N, del Pozo CB, Draper CE, El Hamdouchi A, et al. Promoting healthy movement behaviours among children during the COVID-19 pandemic. Lancet Child Adolesc Health. 2020;4(6):416-8. https://doi.org/10.1016/ s2352-4642(20)30131-0.

33. Ashikkali L, Carroll W, Johnson C. The indirect impact of COVID19 on child health. Paediatr Child Health. 2020;30(12):430-7. https://doi.org/10.1016/j.paed.2020.09.004. This review paper examines the indirect health and psychological effects of the COVID-19 pandemic on children, discusses the implications for parenting and education, and offers strategies for providers to address the emerging challenges.

34. Brazendale K, Beets MW, Weaver RG, Pate RR, Turner-McGrievy GM, Kaczynski AT, et al. Understanding differences between summer vs. school obesogenic behaviors of children: the structured days hypothesis. Int J Behav Nutr Phys. Act. 2017;14(100):114. https://doi.org/10.1186/s12966-017-0555-2..
35. Rundle AG, Park Y, Herbstman JB, Kinsey EW, Wang YC. COVID-19 related school closings and risk of weight gain among children. Obesity (Silver Spring). 2020;28(6):1008-9. https://doi.org/10.1002/oby.22813.

36. Biddle SJH, Asare M. Physical activity and mental health in children and adolescents: a review of reviews. Br J Sports Med. 2011;45(11):886-95. https://doi.org/10.1136/bjsports-2011-090185.

37. Okuyama J, Seto S, Fukuda Y, Funakoshi S, Amae S, Onobe J, et al. Mental and physical activity among children and adolescents during the COVID-19 pandemic. Tohoku J Exp Med. 2021;253(3):203-15. https://doi.org/10.1620/tjem.253.203.

38. Xiang M, Zhang Z, Kuwahara K. Impact of COVID-19 pandemic on children and adolescents' lifestyle behavior larger than expected. Prog Cardiovasc Dis. 2020;63(4):531-2. https://doi. org/10.1016/j.pcad.2020.04.013.

39. Jenssen BP, Kelly MK, Powell M, Bouchelle Z, Mayne SL, Fiks AG. COVID-19 and changes in child obesity. Pediatrics. 2021;147(5): e2021050123. https://doi.org/10.1542/peds. 2021-050123.

40. Pietrobelli A, Pecoraro L, Ferruzzi A, Heo M, Faith M, Zoller T, et al. Effects of COVID-19 on lifestyle behaviors in children with obesity living in Verona, Italy: a longitudinal study. Obesity (Silver Spring). 2020;28(8):1382-5. https://doi.org/10.1002/oby.22861.

41. Golberstein E, Wen H, Miller BF. Coronavirus disease 2019 (COVID-19) and mental health for children and adolescents. JAMA Pediatr. 2020;174(9):819-20. https://doi.org/10.1001/ jamapediatrics.2020.1456.

42. Paulus FW, Ohmann S, Popow C. Practitioner review: school-based interventions in child mental health. J Child Psychol Psychiatry. 2016;57(12):1337-59. https://doi.org/10.1111/jcpp.12584.

43. Fazel M, Patel V, Thomas S, Tol W. Mental health interventions in schools 2: mental health interventions in schools in low-income and middle-income countries. Lancet Psychiatry. 2014;1:388-98. https://doi.org/10.1016/s2215-0366(14)70357-8.

44. Fazel M, Hoagwood K, Stephan S, Ford Tamsin. Mental health interventions in schools 1: mental health interventions in schools in high-income countries. Lancet Psychiatry. 2014;1(5):37787. https://doi.org/10.1016/s2215-0366(14)70312-8.

45. Ali MM, West K, Teich JL, Lynch S, Mutter R, Dubenitz J. Utilization of mental health services in educational setting by adolescents in the United States. J School Health. 2019;89(5):393-401. https://doi.org/10.1111/josh.12753.

46. Dray J, Bowman J, Campbell E, Freund M, Wolfenden L, Hodder RK, et al. Systematic review of universal resilience-focused interventions targeting child and adolescent mental health in the school setting. J Am Acad Child Adolesc Psychiatry. 2017;56(10):81324. https://doi.org/10.1016/j.jaac.2017.07.780.

47. Sanchez AL, Cornacchio D, Poznanski B, Golik AM, Chou T, Comer JS. The effectiveness of school-based mental health services for elementary-aged children: a meta-analysis. J Am Acad Child Adoles Psychiatry. 2018;57(3):153-65. https://doi.org/10. 1016/j.jaac.2017.11.022.

48. National Research Council and Institute of Medicine. Preventing mental, emotional, and behavioral disorders among young people: progress and possibilities. 2009. O'Connell ME, Boat T, Warner KE, editors. Committee on the Prevention of Mental Disorders and Substance Abuse Among Children, Youth, and Young Adults: Research Advances and Promising Interventions. The National Academies Press. https://www.nap.edu/catalog/ 12480/preventing-mental-emotional-and-behavioral-disordersamong-young-people-progress. Accessed 10 May 2021.

49. Pfefferbaum B, Sweeton JL, Newman E, Varma V, Noffsinger MA, Shaw JA, et al. Child disaster mental health interventions, part II. Disaster Health. 2014;2(1):58-67. https://doi.org/10.4161/dish. 27535 . 
50. Fu C, Underwood C. A meta-review of school-based disaster interventions for child and adolescent survivors. J Child Adolesc Ment Health. 2015;27(3):161-71. https://doi.org/10.2989/ 17280583.2015.1117978.

51. American Psychiatric Association. Needs of students during the COVID-19 era: American Academy of Child and Adolescent Psychiatry (AACAP) and American Psychiatric Association (APA) detail steps necessary for safely reopening schools this
Fall. 2020. https://www.psychiatry.org/newsroom/news-releases/ needs-of-students-during-the-covid-19-era-american-academy-ofchild-and-adolescent-psychiatry-aacap-and-american-psychiatricassociation-apa-detail-steps-necessary-for-safely-reopening-schoolsthis-fall. Accessed 5 May 2021.

Publisher's Note Springer Nature remains neutral with regard to jurisdictional claims in published maps and institutional affiliations. 